\title{
A Study of Function Spaces through a Functor
}

\author{
Dr. Pravanjan Kumar Rana
}

Assistant Professor of Department of Mathematics, Ramakrishna Mission Vivekananda Centenary College, Rahara, Kol.118, India

\begin{abstract}
Let $X$ be a locally compact Hausdorff space and let $F_{n}(X)=$ limit of the function spaces of maps of $X$ into certain spaces of type $K(\pi, n)$

$\Rightarrow$ each of the spaces of sequences

$S P^{\infty} \sum^{n}, \Omega S P^{\infty} \sum^{n+1}, \Omega S P^{\infty} \sum^{n+2}, \ldots, \Omega S P^{\infty} \sum^{n+m}, \ldots$ is a space of type $K(\pi, n)$,

$\Rightarrow S P^{\infty} \sum^{n} \rightarrow \Omega S P^{\infty} \sum^{n+1} \rightarrow \Omega^{2} S P^{\infty} \sum^{n+2} \rightarrow \ldots \rightarrow \Omega^{n} S P^{\infty} \sum^{n+m} \rightarrow \Omega^{n+1} S P^{\infty} \sum^{n+m+1} \rightarrow \ldots$.

For any space $X$, we define the space $F_{n, m}(X)=\left(\Omega^{n} S P^{\infty} \sum^{n+m}\right)^{X}$ topologized by the compact-open topology.

The aim of this paper is $i$ ) to investigate the properties of $F_{n, m}(X)$; ii) to study of the object $F_{n, m}$.
\end{abstract}

Keywords: Eilenberg-MacLane space, function spaces, $\Sigma$-homotopy classes, contravariant functor, compact open topology

\section{Introduction}

Throughout this paper we assume that all spaces are locally compact Hausdorff space, also all spaces are of type $K(\pi, n)$.

Now we recall the following the following definitions and statements:-

\section{Definition 1.1:}

Let $\pi$ be a discrete group. A based topological space $X$ is called an Eilenberg-MacLane space of type $\mathrm{K}(\pi ; n)$, where $\mathrm{n} \geq 1$; if all the homotopy groups $\pi_{\mathrm{k}}(\mathrm{X})$ are trivial except

for $\pi_{\mathrm{n}}(\mathrm{X})$; which is isomorphic to $\pi$.

A pointed CW complex $X$ is a $K(\pi, n)$

(Eilenberg-MacLane space) if

$\pi_{\mathrm{k}}(\mathrm{X})=\left\{\begin{array}{l}\pi_{s} k=n \\ 0, k \neq n\end{array}\right.$

\section{Definition 1.2:}

Let $\mathrm{f}: \mathrm{X} \rightarrow \mathrm{Y}$ be a continuous map, define $\Sigma \mathrm{f}: \Sigma \mathrm{X} \rightarrow \Sigma \mathrm{Y}$ by $\Sigma \mathrm{f}(\mathrm{x}, \mathrm{t})=(\mathrm{f}(\mathrm{x}), \mathrm{t})$, then $\Sigma$ is a covariant functor. This implies that $\Sigma$ induces homotopic maps into homotopic maps i.e. $\Sigma$ induces a map

$\Sigma:[\mathrm{X}, \mathrm{Y}] \rightarrow[\Sigma \mathrm{X}, \Sigma \mathrm{Y}]$

Define $\Sigma^{\mathrm{n}+1}(\mathrm{X})=\Sigma\left(\Sigma^{\mathrm{n}} \mathrm{X}\right)$

$\Rightarrow[\mathrm{X}, \mathrm{Y}] \rightarrow[\Sigma \mathrm{X}, \Sigma \mathrm{Y}] \rightarrow \ldots \rightarrow\left[\Sigma^{\mathrm{n}} \mathrm{X}, \Sigma^{\mathrm{n}} \mathrm{Y}\right] \rightarrow \ldots$

$\Rightarrow \lim _{n \rightarrow \infty}\left[\Sigma^{n} X, \Sigma^{n} Y\right]=\{X, Y\}$.

In [5] define that S-category same as $\Sigma$-category is the category whose objects are topological spaces with base points and whose maps are from $\mathrm{X}$ to $\mathrm{Y}$ are the elements of $\{\mathrm{X}, \mathrm{Y}\}$

For any space $X$ we define the space

$F_{n, m}(X)=\left(\Omega^{n} S P^{\infty} \sum^{n+m}\right)^{X}$ topologized by the compact-open topology, then we have the following:

Lemma1.3: Let $X$ be a polyhedron, the map $F_{n, m}(X) \rightarrow$ $F_{n, m+1}(X)$ is a weak homotopy equivalence for each $m \geq 0$.

Proof:
Since $\pi_{k}\left(F_{n_{m} m}(X)\right) \approx\left[\Sigma^{k} X_{v} \Omega^{m} S P^{* s} \Sigma^{n+m}\right]$ and $\pi_{k}\left(F_{n, m+1}(X)\right) \approx\left[\Sigma^{k} X_{v} \Omega^{m+1} S P^{=0} \Sigma^{n+m+1}\right]$,

it follows that the map $F_{n, m}(X) \rightarrow F_{n, m+1}(X)$ is a weak homotopy equivalence for each $\mathrm{m} \geq 0$.

Lemma1.4: Each inclusion map

$\mathrm{F}_{\mathrm{n}, \mathrm{m}}(\mathrm{X}) \subset \mathrm{F}_{\mathrm{n}}(\mathrm{X})$ is a weak homotopy equivalence.

Proof:-

Since $F_{n}(X)$ has the weak topology relative to the subsets $F_{n, m}(X)$, it follows that every subset of $F_{n}(X)$ is contained in $F_{n, m}(X)$ for some $m \geq 0$ (all the function spaces are easily seen to be Hausdorff). Therefore the inclusion maps $\mathrm{F}_{\mathrm{n}, \mathrm{m}}(\mathrm{X}) \subset \mathrm{F}_{\mathrm{n}}(\mathrm{X})$ induce the isomorphism

$\lim _{m} \pi_{q}\left(F_{n_{1} m}(X)\right) \approx \pi_{q}\left(F_{n}(X)\right)$, it follows from

Lemma1.3 that for any $m \geq 0$,

$\pi_{q}\left(F_{n}(X)\right) \approx \lim _{m} \pi_{q}\left(F_{n m}(X)\right)$

Lemma 1.5: Let $\lambda: F_{n+1}(\Sigma X) \rightarrow F_{n}(X)$ be defined by $\lambda(\alpha)$ (x) $\left(\mathrm{t}_{1}, \mathrm{t}_{2}, \ldots, \mathrm{t}_{\mathrm{m}}\right)=\lambda\left(\mathrm{x}, \mathrm{t}_{\mathrm{m}}\right)\left(\left(\mathrm{t}_{1}, \mathrm{t}_{2}, \ldots, \mathrm{t}_{\mathrm{m}-1}\right)\right.$, for $\alpha \in \mathrm{F}_{\mathrm{n}+1, \mathrm{~m}-1}(\Sigma \mathrm{X})$, then $\lambda$ is an isomorphism and if $\mathrm{f}: \mathrm{X} \rightarrow \mathrm{X}^{\prime}$, commutativity holds in the diagram

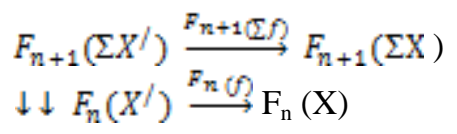

Proof:

Since $\lambda: F_{n+1}(\Sigma X) \rightarrow F_{n}(X)$ is induced by the natural isomorphism

$\lambda^{\prime}: F_{n+1, m-1}(\Sigma X) \rightarrow F_{n, m}(X)$, for every $m \geq 1$ and so $\lambda$ is an isomorphism.

Again since the diagram

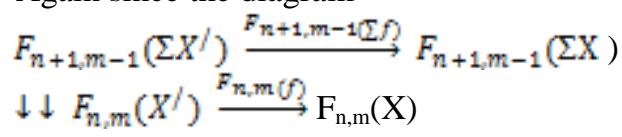

is commutative and so $\lambda$ is commutativity.

Let $\bar{\lambda}:\left[\mathrm{F}_{\mathrm{n}+1}\left(\Sigma \mathrm{X}^{\prime}\right), \mathrm{F}_{\mathrm{n}+1}(\Sigma \mathrm{X})\right] \rightarrow\left[\mathrm{F}_{\mathrm{n}}\left(\mathrm{X}^{\prime}\right), \mathrm{F}_{\mathrm{n}}(\mathrm{X})\right]_{\mathrm{H}}$ be the isomorphism defined by

$\bar{\lambda}[\mathrm{f}]_{\mathrm{H}}=\left[\lambda \mathrm{f} \lambda^{-1}\right]_{\mathrm{H}}$.

Using the above Lemma1.3, it follows that

$\bar{\lambda} \mathrm{F}_{\mathrm{n}+1}(\Sigma)=\mathrm{F}_{\mathrm{n}}:\left\{\mathrm{X}, \mathrm{X}^{\prime}\right\} \rightarrow\left[\mathrm{F}_{\mathrm{n}}\left(\mathrm{X}^{\prime}\right), \mathrm{F}_{\mathrm{n}}(\mathrm{X})\right]_{\mathrm{H}}$.

\section{Volume 5 Issue 6, June 2016 www.ijsr.net}




\section{International Journal of Science and Research (IJSR) \\ ISSN (Online): 2319-7064}

Index Copernicus Value (2013): 6.14 | Impact Factor (2015): 6.391

Therefore we can extend the functor $F_{\mathrm{n}}$ to a functor

$F_{n}^{f}:\left\{X, X^{\prime}\right\} \rightarrow\left[F_{n}\left(X^{\prime}\right), F_{n}(X)\right]_{H}$ such that the following diagram

$$
\begin{aligned}
& {\left[\Sigma^{\mathrm{m}} X_{v} \Sigma^{\mathrm{m}} X^{\ell}\right] \rightarrow\left\{X_{\mathrm{a}} \mathrm{X}^{\prime}\right\}} \\
& \bar{\lambda}{ }^{\mathrm{m}} \mathrm{F}_{\mathrm{n}+\mathrm{m}} \searrow \mathscr{C} F_{\mathrm{n}}^{\ell}
\end{aligned}
$$

$\left[\mathrm{F}_{\mathrm{n}}\left(\mathrm{X}^{\prime}\right), \mathrm{F}_{\mathrm{n}}(\mathrm{X})\right]_{\mathrm{H}}$ is commutative.

Lemma 1.6: $F_{n}^{d}$ is a homomorphism

Proof: We prove that

$\mathrm{F}_{\mathrm{n}+\mathrm{m}}:\left[\Sigma^{\mathrm{m}} X_{v} \Sigma^{\mathrm{m}} X^{f}\right] \rightarrow\left[\mathrm{F}_{\mathrm{n}+\mathrm{m}}\left(\Sigma^{\mathrm{m}} X\right), \mathrm{F}_{\mathrm{n}+\mathrm{m}}\left(\Sigma^{\mathrm{m}} X^{/}\right)\right]_{\mathrm{H}}$ is a homomorphism for $\mathrm{m} \geq 2$.

Let $\mathrm{f}, \mathrm{g}: \Sigma^{\mathrm{m}} X \rightarrow \Sigma^{\mathrm{m}} X^{f}$ such that $\mathrm{x}_{0} \in \mathrm{A} \cap \mathrm{B}, \Sigma^{\mathrm{m}} \mathrm{X}=\mathrm{A} \cup \mathrm{B}, \mathrm{f}^{\prime} \mid \mathrm{B}$ $=\mathrm{g}^{\prime} \mid \mathrm{A}=x_{0}^{\prime}$ and $\mathrm{f} \simeq \mathrm{f}^{\prime}, \mathrm{g} \simeq \mathrm{g}^{\prime}$.

Then $\mathrm{f}^{\prime}+\mathrm{g}^{\prime}: \Sigma^{\mathrm{m}} X \rightarrow \Sigma^{\mathrm{m}} X^{f}$ is defined by

$\mathrm{f}^{\prime}+\mathrm{g}^{\prime}\left|\mathrm{A}=\mathrm{f}^{\prime}\right| \mathrm{A}$ and $\mathrm{f}^{\prime}+\mathrm{g}^{\prime}\left|\mathrm{B}=\mathrm{g}^{\prime}\right| \mathrm{B}$ and

$[\mathrm{f}]+[\mathrm{g}]=\left[\mathrm{f}^{\prime}+\mathrm{g}^{\prime}\right]$.

If $\lambda^{\prime} \in \mathrm{F}_{\mathrm{n}+\mathrm{p}, \mathrm{m}}\left(\Sigma^{\mathrm{p}} \mathrm{X}^{\prime}\right)$ and $\mathrm{x} \in \Sigma^{\mathrm{p}} \mathrm{X}^{\prime}$ then

$\left(\left(F_{n+p, m}\left(f^{\prime}+g^{\prime}\right)\right) \lambda^{\prime}\right) x=\lambda^{\prime}\left(f^{\prime}+g^{\prime}\right)(x)$

$$
=\left\{\begin{array}{l}
\lambda^{f} f^{f}=\left(\left(F_{n+p} f^{b}\right) \lambda^{f}\right) x, \text { if } x \in A \\
\lambda^{f} g^{f} x=\left(\left(F_{n+p} g^{b}\right) \lambda^{b}\right) x, \text { if } x \in B
\end{array}\right.
$$

Since $\left.\left(F_{n+p, m} f^{\prime}\right) \lambda^{\prime}\right) x$ is the constant map if $x \in B$ and $\left(\left(F_{n+p, m}\right.\right.$ $\left.\left.\mathrm{g}^{\prime}\right) \lambda^{\prime}\right) \mathrm{x}$ is the constant map for $\mathrm{x} \in \mathrm{A}$, we see that

$\left(F_{n+p, m}\left(f^{\prime}+g^{\prime}\right)\right) \lambda^{\prime}=\left(\left(F_{n+p, m} f^{\prime}\right) \lambda^{\prime}\right) \cdot\left(\left(F_{n+p, m} g^{\prime}\right) \lambda^{\prime}\right.$,

so $F_{n+p, m}\left(f^{\prime}+g^{\prime}\right)=F_{n+p}, m\left(f^{\prime}\right) \cdot F_{n+p, m}\left(g^{\prime}\right)$,

Lemma1.7: Let $Y$ be a space of type $K(\pi, n)$ and let $X$ be a polyhedron such that $\mathrm{H}^{\mathrm{q}}(\mathrm{X})=0$,

for $\mathrm{q} \geq \mathrm{n}$.

Let $\Delta: \pi_{q}\left(Y^{X}\right) \rightarrow \mathrm{H}^{\mathrm{n}-\mathrm{q}}(\mathrm{X} ; \pi)$ be defined by $\Delta \alpha=\mathrm{E}^{*}(\tau) / \mathrm{h} \alpha$, then $\Delta$ is an homomorphism $\Delta: \pi_{\mathrm{q}}\left(\mathrm{Y}^{\mathrm{X}}\right) \approx \mathrm{H}^{\mathrm{n}-\mathrm{q}}(\mathrm{X} ; \mathrm{H})$

Let $\mathrm{X}$ be a polyhedron such that $\mathrm{H}^{\mathrm{q}}(\mathrm{X})=0$ for $\mathrm{q} \geq \mathrm{n}$, then we have isomorphisms

$\Delta_{n m}: \pi_{\mathrm{q}}\left(\mathrm{F}_{\mathrm{n}, \mathrm{m}}(\mathrm{X})\right) \approx \mathrm{H}^{\mathrm{n}-\mathrm{q}}(\mathrm{X})$ defined by

$\Delta_{\mathrm{n} m} \alpha=E_{n, m}^{*}\left(\tau_{n m}\right) / \mathrm{h} \alpha$, where

$E_{n_{m} \mathrm{~m}}: F_{n_{m} m}(X \times X) \rightarrow \Omega^{\mathrm{m}} \mathrm{SP}^{\infty} \sum^{\mathrm{n}+\mathrm{m}}$ is a evaluation map.

From the commutativity of the diagram

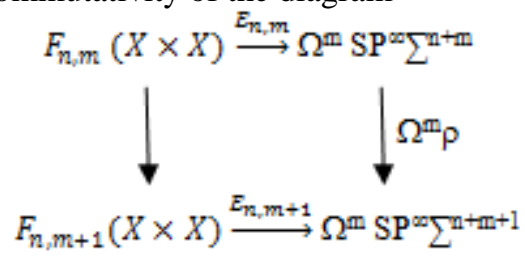

and the fact that $\left(\Omega^{\mathrm{m}} \rho\right)^{*} \tau_{\mathrm{n}, \mathrm{m}+1}=\tau_{\mathrm{n}, \mathrm{m}}$,

we get the commutative diagram

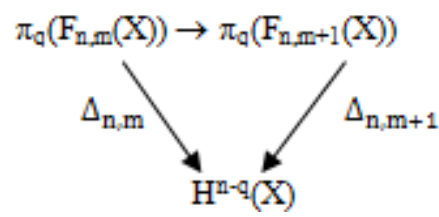

$\Rightarrow \Delta_{n}: \quad \pi_{\mathrm{q}}\left(\mathrm{F}_{\mathrm{n}}(\mathrm{X})\right) \approx \mathrm{H}^{\mathrm{n}-\mathrm{q}}(\mathrm{X})$ is an isomorphism and commutativity holds in the diagram

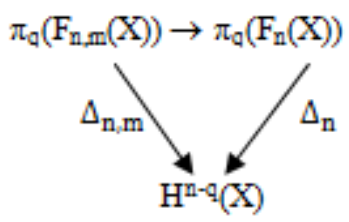

Lemma 1.8:

Let $\mathrm{f}: \mathrm{X} \rightarrow \mathrm{X}^{\prime}$, then the diagram

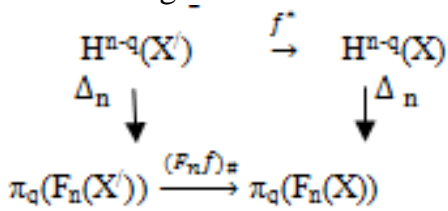

is commutative

Proof: To prove the Lemma it suffices to prove the following diagram is commutative

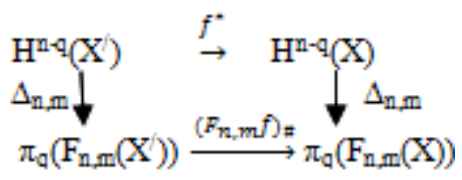

Let i: $F_{n, m}\left(X^{\prime}\right) \subset F_{n, m}\left(X^{\prime}\right), j: X \subset X$. By definition of $F_{n, m}(f)$ we have the commutative diagram

$$
\begin{aligned}
& \mathrm{F}_{\mathrm{n}, \mathrm{m}}(\mathrm{X} \times \mathrm{X}) \stackrel{i \times f}{\rightarrow} \mathrm{F}_{\mathrm{n}, \mathrm{m}}(\mathrm{X} \times \mathrm{X}) \\
& \mathrm{F}_{\mathrm{n}, \mathrm{m}}(\mathrm{f} \times \mathrm{j}) \downarrow \\
& \mathrm{F}_{\mathrm{n}, \mathrm{m}}(\mathrm{X} \times \mathrm{X}) \stackrel{i \times f}{\longrightarrow} \Omega^{m} S P^{\infty} \sum^{n+m}
\end{aligned}
$$

$\mathrm{E}, \mathrm{E}^{\prime}$ are the respective evaluation maps.

Lemma1.9 Let $f_{i}: X \rightarrow Y$ and $g_{i}: Y \rightarrow Z$, for $i=1,2$ be continuous. If $\mathrm{f}_{1} \simeq \mathrm{f}_{2}$ and $\mathrm{g}_{1} \simeq \mathrm{g}_{2}$, then $g_{1} \circ f_{1} \simeq g_{2} \circ f_{2}$; that is $\left[g_{1} \circ f_{1}\right]=\left[g_{2} \circ f_{2}\right]$.

In [1], it follows.

\section{In section 2 we construct and investigate functor $F_{n, m}$}

Theorem 2.1 If $\mathrm{f}: \mathrm{X} \rightarrow \mathrm{X}^{\prime}$,

then $F_{n,}(f): F_{n,}\left(X^{\prime}\right) \rightarrow F_{n,}(X)$ is a continuous homomorphism.

Proof: We define $F_{n, m}(f): F_{n, m}\left(X^{\prime}\right): \rightarrow F_{n, m}(X)$ by

$\left(F_{n, m}\left(f\left(\lambda^{\prime}\right)\right)(x)=\lambda^{\prime}(f(x))\right.$, for $\lambda^{\prime} \in F_{n, m}\left(X^{\prime}\right), m \geq 0$.

Since for every $m, F_{n}(f): F_{n}\left(X^{\prime}\right): \rightarrow F_{n}(X)$ is a continuous homomorphism and

$F_{n}(f) i \mathrm{~F}_{\mathrm{n}, \mathrm{m}}\left(\mathrm{X}^{\prime}\right)=\mathrm{F}_{\mathrm{n}, \mathrm{m}}(\mathrm{f})$ is continuous

Theorem 2.2 Let $\left\{X, X^{\prime}\right\}$ is the set of $\Sigma$-homotopy classes from $X$ to $X^{\prime}$ and $\left[F_{n}\left(X^{\prime}\right), F_{n}(X)\right]_{H}$ denote the monoid of homotopy classes of homomorphisms, homotopic through homomorphisms, of one abelian monoid $F_{n}\left(X^{\prime}\right)$ into another $F_{n}(X)$, then we have a homomorphism

$F_{n}:\left\{X, X^{\prime}\right\} \rightarrow\left[F_{n}\left(X^{\prime}\right), F_{n}(X)\right]_{H}$ such that $F_{n}[f]=\left[F_{n}(f)\right]_{H}$.

Proof: Let $h: X \times I \rightarrow X^{\prime}$ be a homotopy from $f_{0}$ to $f_{1}$. Then for each $\mathrm{m}$ we have a continuous homomorphism $\mathrm{F}_{\mathrm{n}, \mathrm{m}}(\mathrm{h}):\left(\Omega^{\mathrm{m}} S P^{\infty} \Sigma^{\mathrm{n}+\mathrm{m}}\right)^{X^{f}} \rightarrow\left(\Omega^{\mathrm{m}} \quad \mathrm{SP}^{\infty} \sum^{\mathrm{n}+\mathrm{m}}\right)^{\mathrm{X} \times \mathrm{I}} \quad$, which corresponds to a continuous map

$\mathrm{h}_{\mathrm{m}}:\left(\Omega^{\mathrm{m}} S P^{\infty} \Sigma^{\mathrm{n}+\mathrm{m}}\right)^{x^{f}} \times \mathrm{I} \rightarrow\left(\Omega^{\mathrm{m}} \mathrm{SP}^{\infty} \sum^{\mathrm{n}+\mathrm{m}}\right)^{\mathrm{X}}$ which is a continuous homomorphism for every $\mathrm{t} \in \mathrm{I}$.

\section{Volume 5 Issue 6, June 2016} www.ijsr.net 


\section{International Journal of Science and Research (IJSR) \\ ISSN (Online): 2319-7064}

Index Copernicus Value (2013): 6.14 | Impact Factor (2015): 6.391

Since commutativity holds in the diagram

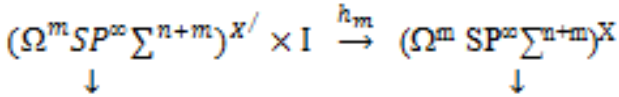

$$
\begin{aligned}
& \left(\Omega^{m+1} S P^{\infty} \sum^{n+m+1}\right)^{X /} \times \mathrm{I} \stackrel{h_{m+1}}{\longrightarrow}\left(\Omega^{\mathrm{m}+1} \mathrm{SP}^{\infty} \sum^{\mathrm{n}+\mathrm{m}+1}\right)^{\mathrm{X}} \\
& \Rightarrow \text { the maps } \mathrm{h}_{\mathrm{m}} \text { define a continuous map } \\
& h^{f}: \lim _{m}\left(\left(\Omega^{m} S P^{s 0} \Sigma^{n+m}\right)^{X^{f}} \times I\right) \rightarrow F_{n} \\
& \Rightarrow \lim _{m}\left(\left(\Omega^{\mathrm{m}} S P^{\infty} \Sigma^{\mathrm{n}+\mathrm{m}}\right)^{X^{f}} \times \mathrm{I}\right) \approx \lim _{m}\left(\Omega^{\mathrm{m}} S P^{\infty} \Sigma^{n+\mathrm{m}}\right)^{x^{\ell}} \times I \\
& \mathrm{~h}^{\prime} \text { defines a continuous map } \mathrm{h}^{\prime \prime}: \mathrm{F}_{\mathrm{n}}\left(\mathrm{X}^{\prime}\right) \times \mathrm{I} \rightarrow \mathrm{F}_{\mathrm{n}}(\mathrm{X}) \\
& \Rightarrow \mathrm{F}_{\mathrm{n}}\left(\mathrm{f}_{0}\right) \simeq \mathrm{F}_{\mathrm{n}}\left(\mathrm{f}_{1}\right)
\end{aligned}
$$

Theorem 2.3 Let $\left\{X, X^{\prime}\right\}$ is the set of $\Sigma$-homotopy classes from $X$ to $X^{\prime}$. The set of all $\Sigma$-homotopy classes and their homomorphisms forms a category, it is denoted by ${ }^{\prime} \mathcal{H C}^{\prime}$

Proof: We take all the Hausdorff spaces are the set of object and the set of $\Sigma$-homotopy classes are set of morphisms and the composition is the usual composition of mappings.

Theorem2.4 $\left[\mathrm{F}_{\mathrm{n}}\left(\mathrm{X}^{\prime}\right), \mathrm{F}_{\mathrm{n}}(\mathrm{X})\right]_{\mathrm{H}}$ denote the monoid of homotopy classes of homomorphisms, homotopic through homomorphisms, of one abelian monoid $\mathrm{F}_{\mathrm{n}}\left(\mathrm{X}^{\prime}\right)$ into another $F_{n}(X)$. The set of all monoid of homotopy classes of homomorphisms, homotopic through homomorphisms forms a category, it is denoted by ${ }^{\prime} \mathcal{F} \mathcal{N} \mathcal{H C}^{\prime}$

Proof: We take all the abelian monoid are the set of object and the set of all monoid of homotopy classes of homomorphisms, homotopic through homomorphisms are set of morphisms and the composition is the usual composition of mappings.

Theorem2.5 Let ${ }^{H} \mathcal{H} \mathcal{C}^{f}$ be the category of homotopy classes of homomorphism and ${ }^{\prime} \mathcal{F} \mathcal{N} \mathcal{H} e^{f}$ be the monoid of homotopy classes of homomorphisms, there exists a contravariant n- homotopy functor $\mathcal{F}_{n}:{ }^{n} \mathcal{H} \mathrm{C}^{t} \rightarrow{ }^{f} \mathcal{F} \mathcal{N} \mathcal{H} \mathrm{C}^{f}$

\section{Proof:}

Let $\left\{X, X^{\prime}\right\}$ be the set of $\Sigma$-homotopy classes from $X$ to $X^{\prime}$ in ${ }^{\prime} \mathcal{H} \mathcal{C}^{\prime}$ then $\left[\mathrm{F}_{\mathrm{n}}\left(\mathrm{X}^{\prime}\right), \mathrm{F}_{\mathrm{n}}(\mathrm{X})\right]_{\mathrm{H}}$ denote the monoid of homotopy classes of homomorphisms, homotopic through homomorphisms, of one abelian monoid $F_{n}\left(X^{\prime}\right)$ into another $\mathrm{F}_{\mathrm{n}}(\mathrm{X})$ in 'F $\mathcal{F} \mathcal{H} \mathcal{H} \mathcal{C}^{\prime}$.

Let $\left\{\mathrm{X}_{1}, \mathrm{X}_{2}\right\}$ be the set of $\Sigma$-homotopy classes from $\mathrm{f}: \mathrm{X}_{1} \rightarrow$ $\mathrm{X}_{2}$ and $\left\{\mathrm{X}_{2}, \mathrm{X}_{3}\right\}$ be the set of $\Sigma$-homotopy classes from $\mathrm{g}: \mathrm{X}_{2}$ $\rightarrow X_{3}$, then by Definition1.2 and Lemma1.9, $\left\{X_{1}, X_{3}\right\}$ be the set of $\Sigma$-homotopy classes from gf: $\mathrm{X}_{1} \rightarrow \mathrm{X}_{3}$ in ${ }^{5} \mathcal{H} \mathcal{C}^{\prime}$ and also for $\left\{X_{1}, X_{3}\right\}$ be the set of $\Sigma$-homotopy classes from $\mathrm{gf}$ $: \mathrm{X}_{1} \rightarrow \mathrm{X}_{3}$ in ${ }^{\prime} \mathcal{H} \mathcal{C}^{\prime}$, then $\left[\mathrm{F}_{\mathrm{n}}\left(\mathrm{X}_{3}\right), \mathrm{F}_{\mathrm{n}}\left(\mathrm{X}_{1}\right)\right]_{\mathrm{H}}$ denote the monoid of homotopy classes of homomorphisms, homotopic through homomorphisms, of one abelian monoid $\mathrm{F}_{\mathrm{n}}\left(\mathrm{X}_{3}\right)$ into another

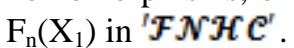

$F_{n}:\left\{X_{1}, X_{3}\right\} \rightarrow\left[F_{n}\left(X_{3}\right), F_{n}\left(X_{1}\right)\right]_{H}$ such that $F_{n}[g ~ f]=\left[F_{n}(g\right.$ f) $]_{H}$. Using the Lemma 1.9, we have if $f \simeq g \Rightarrow F_{n}(f)$ $\simeq F_{n}(g) \Rightarrow\left[F_{n}(f)\right]=\left[F_{n}(g)\right]$. Using Theorem2.2,

$F_{n}[g \circ f]=\left[F_{n}(g \circ f)\right]_{H}=\left[F_{n}(f) o F_{n}(g)\right]_{H}=\left[F_{n}(f)\right]_{H} \circ\left[F_{n}(g)\right]_{H}$. If $\{\mathrm{X}, \mathrm{X}\}$ be the set of $\Sigma$-homotopy classes from $\mathrm{X}$ to $\mathrm{X}$ in ${ }^{\prime} \mathcal{H} \mathcal{C}^{\prime}$ then $\left[\mathrm{F}_{\mathrm{n}}(\mathrm{X}), \mathrm{F}_{\mathrm{n}}(\mathrm{X})\right]_{\mathrm{H}}$ denote the monoid of homotopy classes of homomorphisms, homotopic through homomorphisms, of one abelian monoid $\mathrm{F}_{\mathrm{n}}(\mathrm{X})$ into another $\mathrm{F}_{\mathrm{n}}(\mathrm{X})$ in $" \mathcal{F} \mathcal{N} \mathcal{H} \mathcal{C}^{\prime \prime}$ that is

$\mathrm{F}_{\mathrm{n}}\left[\mathrm{I}_{\{\mathrm{X}, \mathrm{X}\}}\right]=I_{\left[p_{\mathrm{n}}(X) p_{\mathrm{n}}(X)\right]_{H}}$

Theorem 2.6 The set of all monoid of homotopy classes of continuous homomorphism forms a category, it is denoted by ${ }^{\prime} \mathcal{F} \mathcal{N} \mathcal{M} \mathcal{H} \mathrm{C}^{\prime}$.

Proof: We take all the abelian monoid are the set of object and the set of all monoid of homotopy classes of continuous homomorphisms, homotopic through continuous homomorphisms are set of morphisms and the composition is the usual composition of continuous mappings.

Theorem 2.7 Let 'He' ${ }^{f}$ be the category of homotopy classes of homomorphism and ${ }^{\prime} \mathcal{F} \mathcal{N} \mathcal{M} \mathcal{H} \mathcal{C}^{\prime}$ be the category of homotopy classes of continuous homomorphisms, then there exists a contravariant $(\mathrm{n}, \mathrm{m})$ functor $\mathcal{F}_{\mathrm{n} m}:{ }^{*} \mathcal{H C}^{\prime} \rightarrow$ "FNMTHC"

Proof: Using the Theorem2.1, Theorem 2.2 and Theorem 2.5, it follows

\section{Acknowledgement}

This paper was written while the author was got a grant under Minor Research Project of University Grant Commission, reference No. F. PSW-092/13-14 (ERO) dt 18.3.2014.

\section{References}

[1] S.Eilenberg and J.A.Zilber, Semi-simplicial complexes and singular homology, Ann. of Math., 51(1950), 499513.

[2] R.H.Fox, On topologies for function spaces, Bull. Amer. Math.Soc.,51(1945), 429-432

[3] N. Steenrod, Homology groups of symmetric groups and reduced power operations, Proc. Nat. Acad. Sci. U.S.A.,39(1953), 213-217.

[4] S.Eilenberg and N. Steenrod, Foundations of Algebraic Topology, Princeton University Press, 1952.

[5] E.Spanier and J.H.C.Whitehead, Carriers and S-theory, in Algebraic Geometry and Topology.

[6] Spanier H. Algebraic topology, Tata Mc-Graw-Hill Pub. Co. Ltd,1966.

[7] Adhikary M.R. Groups, Rings and Modules with Applications Universities Press, India,1999.

[8] Avishek Adhikari and P.K.Rana, A Study of Functors Associated with Topological Groups, Studia Univ, Babes-Balyai, Mathematica, Vol.XIVI, Number 4, December 2001.

[9] P.K.Rana, A study of functors associated with rings on continuous functions, JIAM,2011, Vol.33(1),73- 78.

[10] P.K.Rana, A study of some functors and their Relations", The Journal of Indian Academy of Mathematics(JIAM) Vol.34,no-1,2012,73-81.

[11] P.K.Rana. A Space Having the Homotopy Type with Fuzzy Modules, IJSR,Volume 3 Issue 10, October 2014 


\section{International Journal of Science and Research (IJSR) \\ ISSN (Online): 2319-7064}

Index Copernicus Value (2013): 6.14 | Impact Factor (2015): 6.391

\section{Author Profile}

Prof. Pravanjan Kumar Rana obtained his MSc in Pure Mathematics and his $\mathrm{PhD}$ in Algebraic Topology. He has published, since 2005, more than 23 papers in peer reviewed journals. Formerly, he was the first HOD of Mathematics Department in Berhampore Girls' College, Berhampore, Murshidabad and latterly he is HOD of Mathematics Department in Ramakrishna Mission Vivekananda Centenary College, Rahara, Kol. 700118,and performs his research at Algebraic Topology and Category Theory.

Volume 5 Issue 6, June 2016 www.ijsr.net 